\title{
Genotipificación y análisis filogenético de cepas colombianas del virus Dengue Tipo 2
}

\author{
Jairo A. Méndez $\quad{ }^{1 *}$, María del P. Bernal $\quad{ }^{1}$, Dora de Calvache ${ }^{1}$ y Jorge Boshell ${ }^{1}$. \\ ${ }^{1}$ Laboratorio de Virología, Grupo Arbovirus, Instituto Nacional de Salud (I.N.S.), Bogotá, Colombia. \\ Recibido: 03-07-03; Aceptado: 12-09-03

\section{RESUMEN}

El virus del Dengue, un flavivirus transmitido por mosquitos del género Aedes, es responsable de un creciente problema de salud pública en áreas tropicales de todo el mundo, con más de 3.000 millones de personas en riesgo de infección. Este virus produce un espectro de síntomas que varía desde un malestar semejante al resfriado común, conocido como dengue clásico, hasta una enfermedad que puede ser fulminante denominada «dengue hemorrágico». La caracterización genética de los diferentes serotipos del virus permite no sólo entender los patrones epidémicos de distribución sino, además, demostrar la presencia de cepas hemorragíparas específicas como responsables de los casos más severos de la enfermedad. En este trabajo determinamos los ancestros evolutivos de los virus Dengue tipo 2 que han circulado en Colombia antes y después de la aparición del dengue hemorrágico a finales de 1989, mediante la secuenciación y análisis de un fragmento de 240 pb de la región de unión de los genes E/NS1 del virus; así, con las secuencias obtenidas de 5 cepas aisladas antes de 1989 y 10 identificadas en años posteriores, se construyó un árbol filogenético que sugiere la presencia de 2 genotipos diferentes en nuestro medio; la comparación con cepas aisladas de diferentes partes del mundo demuestra que uno de estos genotipos corresponde a cepas nativas americanas aisladas antes de la aparición del dengue hemorrágico, mientras que los virus encontrados posteriormente pertenecen al genotipo asiático, indicando el posible desplazamiento de las cepas autóctonas por genotipos posiblemente más agresivos.

Palabras Claves: Genotipificación, análisis filogenético, cepas colombianas, virus Dengue tipo 2.

\begin{abstract}
Genotyfication and philogenetics analysis of Colombian isolated, the Denge Virus Type 2

Dengue virus is a flavivirus transmitted by the mosquito Aedes spp. and is the causative agent for an increasing public health problem in tropical areas over the world, with almost 3.000 million people at risk of infection. Dengue virus produces a broad spectrum of symptoms, varying from a mild flu-like illness called dengue fever, to a severe and some times fulminating haemorrhagic fever disease with shock. Genetic caracterization of distinct virus serotypes allow us to understand the epidemiological patterns of distribution as well as to demonstrate the presence of specific haemorrhagic strains causing very severe disease and death. In this report, we have determined the evolutionary origins of Dengue Virus Type 2 circulating in Colombia before and after the first
\end{abstract}

\footnotetext{
* Correspondencia: Jairo A. Méndez R. Laboratorio de virología, Av./Calle 26 No. 51-60, Bogotá D.C. - Colombia. Tel: +54(1)2207700 ext 549. Fax +54(1)2200928 - E-mail: jairoandres46@hotmail.com
} 
reported haemorrhagic fever case at the ends of 1989, by means of sequence and further analysis of a $240 \mathrm{pb}$ PCR amplified fragment from the E/NS1 joining region; with the sequences obtained from 5 strains isolated before 1989 and 10 from strains isolated years after, a phylogenetic tree was constructed which showed the presence of 2 different genotypes in our country; comparison with strains previously isolated from around the world determined that one of the genotypes found corresponds to the native American genotype circulating before the appearance of haemorrhagic fever, while the later isolated strains of the second genotype belonged to a Southeast Asian genotype, suggesting displacement of the native strains by more virulent genotypes.

Keywords: Genotyfication, phiologenetics analysys, Colombian isolated, Dengue Virus Type 2.

\section{Introducción}

Durante los últimos años, el mundo entero se ha enfrentado a la reemergencia de diferentes enfermedades infecciosas siendo el Dengue, en cualquiera de sus manifestaciones, una de las más importantes en términos de morbilidad y mortalidad (15). La fiebre de Dengue, conocida también como «Dengue clásico», puede ser asintomática o presentarse como una enfermedad aguda caracterizada por fiebre, cefalea, mialgias, artralgias, leucopenia y frecuentemente un brote maculopapular; es una enfermedad autolimitante cuyo tratamiento es exclusivamente sintomático y tiene una mortalidad prácticamente nula $(2,3)$. Por otro lado, la forma severa del Dengue o «Dengue hemorrágico» inicia con un cuadro típico, pero aproximadamente a los 6 días de evolución aparecen hemorragias, evidentes por la aparición espontánea de petequias o mediante una prueba de torniquete positiva. La hemoconcentración acompañada de una marcada trombocitopenia son los hallazgos más importantes para guiar el diagnóstico; en los casos más graves o sin tratamiento de soporte, puede haber una marcada pérdida de plasma que genera colapso circulatorio manifestado por hipotensión, pulso acelerado, hipotermia y síntomas neurológicos que llevan rápidamente a un estado de choque profundo con aumento de hemorragias gastrointestinales y alta mortalidad.

El virus del Dengue es transmitido principalmente por el mosquito vector hematófago Aedes aegypti, y pertenece a la familia flaviviridaedonde se encuentran otros virus estrechamente relacionados como el de la fiebre amarilla $(4,5)$. El genoma viral está constituido por una hebra sencilla de ARN de polaridad positiva, aproximadamente de $11 \mathrm{~kb}$, que presenta un único marco de lectura abierto, el cual codifica para 3 proteínas estructurales (C, prM y E) y 7 proteínas no estructurales (NS1, NS2a, NS2b, NS3, NS4a, NS4b y NS5); mediante técnicas serológicas con anticuerpos monoclonales se han demostrado 4 variedades o serotipos virales (DEN-1, DEN-2, DEN-3, DEN-4) cada uno de los cuales es capaz de causar la enfermedad (1-5). Aunque los mecanismos moleculares precisos por los cuales el virus del Dengue causa enfermedad hemorrágica severa no han sido completamente definidos, se acepta que una segunda infección con un serotipo heterólogo al que causó la primera, incrementa el riesgo de desarrollar Dengue hemorrágico severo (Amplificación Inmunológica de la Infección Mediada por Anticuerpos) (6). Una explicación alternativa a la patogénesis de la enfermedad (no necesariamente excluyente) indica que el alarmante incremento de las formas más severas de la infección por el virus del Dengue puede ser consecuencia de la introducción de cepas virulentas provenientes de zonas endémicas, en ecosistemas donde la enfermedad no había ocurrido previamente (7-11). Así, las herramientas epidemiológicas actuales apoyadas por técnicas de biología molecular han facilitado el estudio y genotipificación de los virus del 
Dengue aislados en diversas zonas tropicales y subtropicales donde la actividad viral es más alta, mediante el análisis de pequeñas secuencias genómicas que permiten detectar variaciones puntuales que no pueden ser demostradas serológicamente; de esta manera, se han demostrado 5 genotipos diferentes para DEN-1(10), 5 genotipos para DEN-2 $(10,11), 2$ genotipos DEN-3 (12) y 2 genotipos DEN-4 $(13,14)$. Aunque los cuatro serotipos del Dengue han circulado siempre en territorio americano causando enfermedad leve y esporádicos casos severos, sólo hasta 1981 ocurrió en Cuba la primera gran epidemia de Dengue hemorrágico en las Américas reportando 10.312 casos severos y 158 casos fatales (1-3); la rápida propagación de la enfermedad llevo a epidemias posteriores en Jamaica (1981-1982), Venezuela (1989-1990) y Brasil (1990), hasta extenderse en gran parte de Centro y Suramérica (1-3). En Colombia el primer caso confirmado de Dengue hemorrágico fue reportado en diciembre de 1989 en Puerto Berrío (Antioquia) y desde entonces, se ha observado una tendencia al rápido incremento en el número de casos, pasando de 1,4 por cada 100.000 habitantes en 1994 a 2,64 casos por 100.000 en 1999, elevándose además la mortalidad (1518). Durante estas epidemias fue posible demostrar mediante aislamiento y tipificación serológica la infección predominante por virus Dengue tipo 2 (DEN2); pero sólo hasta 1997, Rico-Hesse, et al., demostraron la introducción de cepas pertenecientes al genotipo asiático en territorio americano, constituyendo una evidencia clara de la responsabilidad directa de algunas cepas hemorragíparas o de mayor virulencia en la aparición del Dengue hemorrágico (11). Análisis filogenéticos realizados posteriormente por Sariol y colaboradores a partir de muestras hepáticas conservadas en parafina desde la epidemia de Cuba en el año 81 permitieron reforzar estos hallazgos (19). Ya que en los trabajos previamente realizados no fue posible analizar un número representativo de aislamientos colombianos, es nuestro interés mediante este estudio determinar los ancestros evolutivos de las cepas DEN-2 que han circulado en nuestro territorio desde la aparición del Dengue hemorrágico, y compararlas con las cepas autóctonas colombianas que circularon previamente.

\section{Materiales y métodos}

Virus: Los virus de Dengue utilizados fueron seleccionados del banco de cepas del laboratorio de Virología del I.N.S.; 5 cepas aisladas antes de 1990 y 10 cepas aisladas posteriormente en diferentes departamentos de Colombia fueron usadas para infectar células C6/36 de mosquito y los virus fueron identificados como Dengue tipo 2 (DEN-2) tanto por Inmunofluorescencia Indirecta con anticuerpos monoclonales, como por amplificación molecular con iniciadores tipoespecíficos (20). Todas las cepas fueron aisladas a partir de muestras de suero enviadas por los diferentes laboratorios de salud pública para diagnóstico de Dengue.

Extracción de ARN y RT-PCR: Se tomaron $300 \mu \mathrm{L}$ de sobrenadante de cada cultivo, los cuales fueron tratados con $700 \mu \mathrm{L}$ del reactivo de TRIZOLLS ${ }^{\circledR}$ (GIBCO BRL) (21) durante 5 minutos; posteriormente se adicionaron $200 \mu \mathrm{L}$ de cloroformo y se agitaron por 15 segundos; mediante centrifugación a $12.000 \mathrm{rpm}$ por 15 minutos se obtuvo una fase acuosa, la cual fue separada y tratada con $500 \mu \mathrm{L}$ de isopropanol frío durante 10 minutos; después de centrifugar a 12.000 rpm por 10 minutos, el ARN obtenido se lavó con $500 \mu \mathrm{L}$ de etanol al $75 \%$ y posteriormente se resuspendió en agua tratada con dietilpirocarbonato (DEPC, SIGMA) y con 20 unidades de inhibidor de RNAsas (CPG INC.); $15 \mu \mathrm{L}$ del ARN fueron sometidos a la reacción de transcripción reversa (RT) bajo las siguientes condiciones: $5 \mu \mathrm{L}$ de buffer $6 \mathrm{x}$ para transcripción (NEW ENGLAND BIOLAB) $3 \mu \mathrm{L}$ de dithiotreitol (DTT) $0.1 \mathrm{M}$ (SIGMA), $1.5 \mu \mathrm{L}$ de cada uno de los desoxinucleótidos trifosfato (dNTP's) $10 \mathrm{mM}$ (CPG INC.), $1.5 \mu \mathrm{L}$ de transcriptasa reversa M-MLV 
$200 \mathrm{u} / \mu \mathrm{L} \quad(\mathrm{NEW} \quad$ ENGLAND BIOLABS y $3 \mu \mathrm{L}$ del iniciador antisentido D2/2578 (11), $10 \mu \mathrm{M}$; la reacción de transcripción reversa se realizó a $37^{\circ} \mathrm{C}$ durante 1 hora y el ADNc generado se utilizó como templado en una reacción de PCR con los iniciadores previamente reportados $(10,11)$, en las siguientes condiciones: $5 \mu \mathrm{L}$ de buffer de PCR 10x (CPG INC.), $1 \mu \mathrm{L}$ de dNTP's (mezcla con $10 \mathrm{mM}$ de cada uno, CPG INC.), $1 \mu \mathrm{L}$ de iniciador sentido (D2/2170v) $10 \mu \mathrm{M}, 1 \mu \mathrm{L}$ de iniciador antisentido (D2/2578) $10 \mu \mathrm{M}$ y $2.5 \mathrm{U}$ de taq polimerasa (CPG INC.), en un volumen final de $50 \mu \mathrm{L}$; la reacción fue realizada en un termociclador (PERKIN ELMER) con 35 ciclos de denaturación $\left(94^{\circ} \mathrm{C}\right)$, anillaje $\left(55^{\circ} \mathrm{C}\right)$ y extensión $\left(72^{\circ} \mathrm{C}\right)$. Los productos de amplificación obtenidos para cada reacción de PCR fueron purificados a partir de gel de agarosa al $1 \%$ con el estuche de purificación de productos de PCR MoBio, siguiendo las instrucciones del fabricante.

Secuenciación de los fragmentos de PCR y análisis filogenético: Los fragmentos purificados fueron secuenciados con la pareja de iniciadores previamente reportados D2/2170v y D2/2578 (10-11), usando el método automático de ABI Prism 310 (Applied Biosysten) siguiendo las instrucciones del proveedor. Las secuencias obtenidas fueron alineadas con el programa CLUSTAL X, donde además se generaron los árboles filogenéticos que fueron visualizados posteriormente en el programa TREEVIEW. La construcción de los árboles filogenéticos está basada en el método de algoritmos neighbour-joining(22) y su confiabilidad fue estimada usando el método de bootstrap con 1000 repeticiones; además, para definir la raíz inicial del árbol se utilizaron 2 secuencias representativas de virus DEN-3.

Resultados

Se evaluaron 15 cepas DEN-2, de las cuales 5 fueron aisladas antes de 1990 y 10 obtenidas posteriormente. Todas fueron amplificadas con los iniciadores D2/2170v y D2/2578 para generar el fragmento de $408 \mathrm{pb}$ de la región de unión de los genes E/NS1 que fue posteriormente secuenciado; sin embargo, los alineamientos fueron realizados con 240 pb comprendidas dentro del fragmento amplificado, ya que este fragmento brinda las condiciones adecuadas para el análisis filogenético $(10,11)$. En los alineamientos de las cepas colombianas se observó que existe variabilidad en la mayoría de las secuencias evaluadas, 


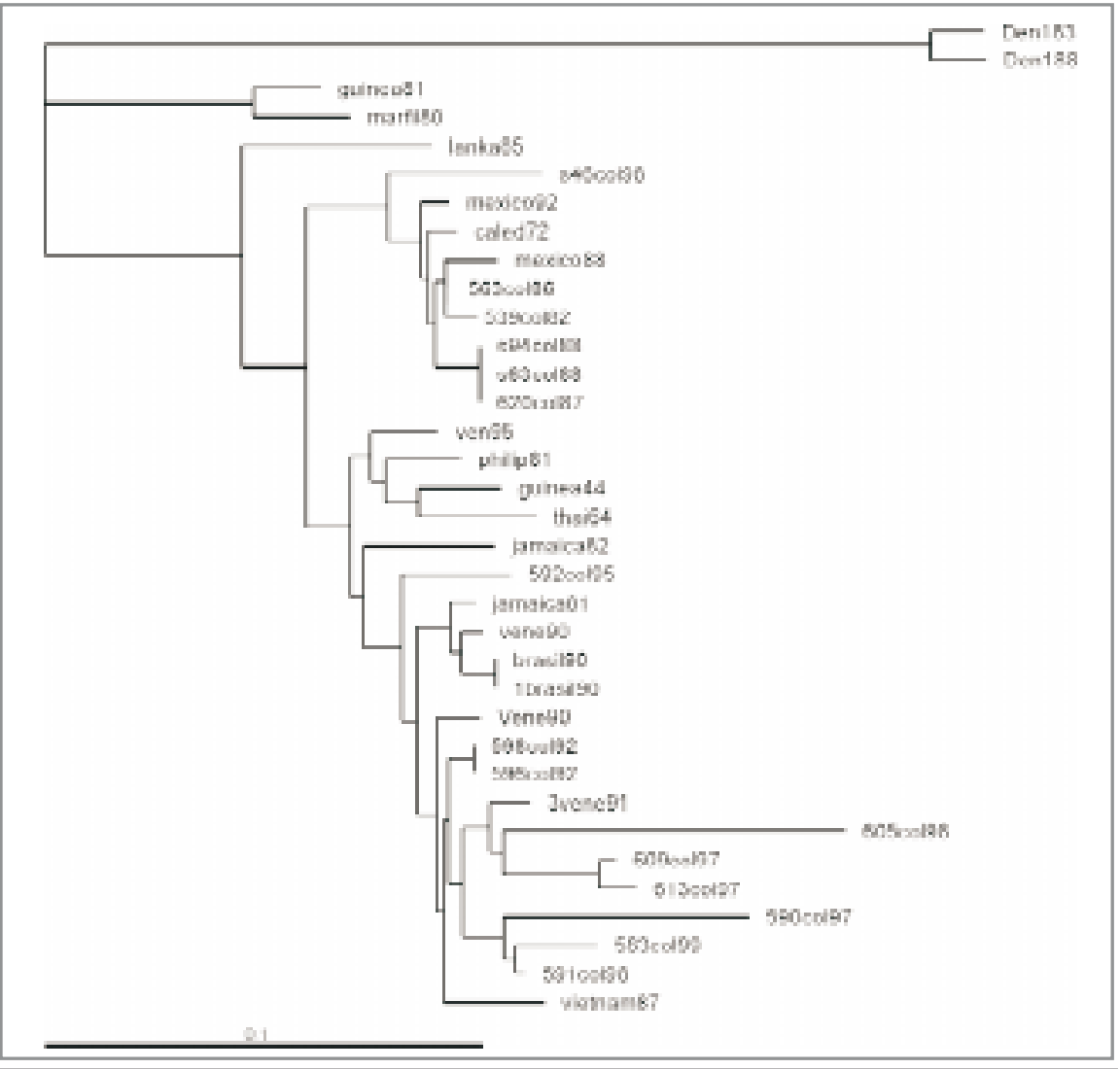

Figura 2. Árbol filogenético que compara las cepas colombianas secuenciadas con cepas de todo el mundo y que representan los 5 genotipos propuestos para dengue tipo 2 .

80 (definidas originalmente como representantes del ciclo selvático africano); el segundo genotipo es una cepa de Sri Lanka/85 (donde se encuentran también cepas de Indonesia, Seychelles y Burkina Faso); un tercer genotipo incluye las cepas colombianas $0446 \mathrm{col} / 98$, $563 \mathrm{col} / 86,539 \mathrm{col} / 82,094 \mathrm{col} / 88$, $863 \mathrm{col} / 88$ y $620 \mathrm{col} 87$, junto con las cepas México/88/92 y una cepa de Nueva Caledonia/72. El cuarto grupo genotípico incluye los aislamientos Venezuela/95, Filipinas/81, Nueva Guinea/44 y Tailandia/64; y, finalmente, el quinto grupo incluye las 9 cepas restantes de Colombia aisladas después de 1990 junto con aislamientos de Jamaica/81/82, Venezuela/90/91, Brasil/90 y Vietnam/87. El valor de Bootstrap

aunque algunas de las cepas aisladas en diferentes espacios geográficos y temporales (094-Caqueta/88, 863-Tólima/88, 620-Tólima/87) presentan secuencias idénticas, lo que refleja la estabilidad en el tiempo de un genotipo dado y su expansión de un lugar a otro. Por otro lado, el árbol filogenético generado a partir de estas secuencias mediante análisis de máxima parsimonia (Figura 1), indica la separación de 2 ramas claramente definidas, una de las cuales agrupa las 5 cepas aisladas antes de 1989 y una cepa aislada en 1998, mientras la otra está constituida por los restantes 9 aislamientos posteriores a 1989. Para determinar a qué genotipo pertenecen los aislamientos evaluados, se construyó un árbol incluyendo cepas aisladas en diferentes partes del mundo, representativas de los 5 genotipos descritos previamente por Rico-Hesse et al. $(10,11)$ (Figura 2). El primer genotipo está constituido por las cepas de Nueva Guinea/81 y Costa de Marfil/ entre los 5 grupos genotípicos varía entre el 99 y $77 \%$ lo cual respalda los patrones de ramificación definidos en la figura 2. Las agrupaciones mostradas en este árbol filogenético fueron generadas mediante el análisis Neighbor-joining y demuestran la estrecha relación existente entre las cepas aisladas en Colombia antes de 1989 con cepas mexicanas que previamente se habían ubicado en lo que se denominó el "genotipo americano", así como la relación filogenética de las cepas aisladas en Colombia después de 1990 con cepas del sureste asiático, tales como las de Vietnam y Tailandia (estas últimas se ubicaron originalmente en este grupo, pero no se muestran en la figura 2), y con las cepas de Jamaica que se cree representan la expansión de las cepas cubanas que generaron la aparición del Dengue hemorrágico en 1981 (11,23-25). 


\section{Discusión}

Durante los decenios de 1950 y 1960, el éxito de las campañas para eliminar la fiebre amarilla urbana mediante la erradicación de Aedes aegyptilogró también reducir de forma significativa la transmisión de Dengue; sin embargo, a medida que se deterioraron las campañas de erradicación durante las décadas de 1970 y 1980, el mosquito proliferó y se propagó por casi todo el territorio americano (1-5). Así no resulta pues sorprendente que la actividad del Dengue se intensificara alcanzando niveles alarmantes durante esa última década, siendo el hecho más relevante la aparición de las formas más severas de Dengue durante 1981 en Cuba, donde ocurrió el primer gran brote de Dengue hemorrágico $(1-3,19)$ que rápidamente se propagó a Jamaica, Venezuela y Brasil. En Colombia, las predicciones realizadas por Hernando Groot sobre la importancia que llegaría a tener esta enfermedad fueron ignoradas durante los años $60 \mathrm{y}$ 70, y, desafortunadamente, ahora se están viviendo de manera estremecedora (4,5,15-18). La fuerza que tienen nuestras epidemias de Dengue y Dengue hemorrágico es compleja e inevitable debido a los cambios económicos y sociales que han generado una urbanización acelerada, en simultánea con el incremento sostenido de la población de mosquitos vectores del Dengue $(4,5)$. Teniendo en cuenta el dramático incremento en la transmisión del virus por todo el mundo durante los últimos 60 años, es posible que se haya incrementado además la tasa de mutación y propagación de genotipos más virulentos, por lo cual, la caracterización genética de cepas del mismo serotipo se ha convertido en una herramienta vital para entender los patrones de distribución del Dengue y la relación de cepas hemorragíparas específicas con la expansión del Dengue hemorrágico (7-14,23-27). Así, una forma mucho más sensible que las técnicas serológicas para clasificar los virus consiste en la comparación de secuencias génicas de un segmento dado del ácido nucleico viral (10,11,26-30); cuando dichas secuencias tienen un mismo ancestro evolutivo es posible generar árboles que señalan el origen y las relaciones filogenéticas de las cepas estudiadas. De esta manera, se ha tratado de identificar el origen de las cepas virales involucradas con la aparición del Dengue hemorrágico en territorio americano, y se ha podido demostrar una asociación directa entre la introducción de cepas del sureste asiático en Cuba con el repentino incremento de casos severos de la enfermedad (11,19). Los análisis filogenéticos realizados con secuencias obtenidas mediante la detección y amplificación por RT-PCR a partir de muestras de tejido de casos fatales producidos durante la epidemia cubana, indican la presencia de una cepa Dengue tipo 2 (estrechamente relacionada con las cepas más antiguas de Nueva Guinea y Tailandia), que además corresponde al mismo virus que poco tiempo después causó brotes de Dengue hemorrágico en Jamaica, demostrando un claro desplazamiento y propagación hacia un territorio geográficamente cercano $(11,19)$. De igual forma, los árboles filogenéticos generados en nuestro estudio con las secuencias virales de aislamientos colombianos, reflejan claramente la presencia del genotipo nativo americano durante los años previos a la aparición del primer caso severo de Dengue, cuando el virus tipo 2 sólo causaba un cuadro típico de Dengue clásico con intensidad variable de los síntomas. En este mismo grupo se incluye además una cepa de Nueva Caledonia, que se cree tiene su origen en la cepa más antigua de Trinidad (TR1751-1954, no incluida en este análisis) (11) que constituye el origen filogenético de las cepas americanas. Por otro lado, 9 de las 10 cepas aisladas después de 1990 se encuentran estrechamente relacionadas con los aislamientos de Vietnam y con las cepas de Jamaica que, como se mencionó anteriormente, pertenecen a la misma cepa cubana que inició el Dengue hemorrágico en 1981 (11,19). Aunque falta un modelo animal adecuado que permita demostrar experimentalmente la hipótesis según la cual las cepas del sureste asiático son las directas responsables de la aparición y expansión del Dengue hemorrágico en nuestro territorio, la evidencia filogenética y epidemiológica presentada confirma los análisis previamente reportados que indican 
claramente el desplazamiento de las cepas autóctonas, por la importación e introducción de virus que no habían circulado previamente y que además coincide con la aparición del Dengue hemorrágico. Una vigilancia epidemiológica adecuada debe incluir el monitoreo de genotipos circulantes que permita predecir y prevenir la expansión de brotes de enfermedad severa, así como el análisis filogenético de los virus Dengue tipo 1, tipo 3 y tipo 4, de los cuales se ha podido demostrar la presencia de diversas variantes genéticas que también pueden involucrarse en la manifestación del Dengue hemorrágico.

\section{REFERENCIAS}

1. Organización Panamericana de la Salud. Dengue y Dengue Hemorrágico en las Américas: Guías para su Prevención y Control. Publicación científica 548; 1995.

2. Gubler DJ, Clark GG. Dengue/Dengue Haemorrhagic Fever: The Emergence of a Global Health Problem. Emerging Infect 1995;Dis 1:55-7.

3. Pan American Health Organization. Dengue and Dengue Haemorrhagic Fever in the Americas: An Overview of the Problem. Epidemiol Bull 1992;13:9-10.

4. Groot H. The Reinvasion of Colombia by Aedes aegypti Aspects to Remember. Am J Trop Med Hyg 1980;29(3):3308

5. Boshell J. El Dengue. Innovación y Ciencia 1995;4(5):46-50.

6. Halstead S. Antibody, Macrophages, Dengue Virus Infection, Shock and Haemorrhage: A Pathogenetic cascade. Rev Infect Dis 1989;11(s4):830-9.

7. Sabin AB. The Dengue Group of Viruses and its Family Relationships. Bacteriol Rev 1950;14:225-35.

8. Hamon W, et al. Virus Associated With Epidemic Hemorrhagic Fevers of the Philippines and Thailand. Science 1960;131:1102-3.

9. Rosen L. The Emperor's New Clothes Revisited, or Reflections on the Pathogenesis of Dengue Hemorrhagic Fever. Am J Trop Med Hyg 1977;26:337-43.

10. Rico-Hesse R. Molecular Evolution and Distribution of Dengue Viruses Type 1 and 2 in Nature. Virol 1990;174:479-93.

11. Rico-Hesse R, et al. Origins of Dengue Type 2 Viruses Associated With Increased Pathogenicity in the Americas. Virol 1997;230:244-51

12. Chungue E, et al. Molecular Epidemiology of Dengue 3 Viruses and Genetic Relatedness Among Dengue 3 Strains Isolated From Patiens With Mild or Severe Form of Dengue Fever in Frensh Polynesia. J Gen Virol 1993;74:2765-70.
13. Chungue E, et al. Molecular Epidemiology of Dengue-1 and Dengue-4 Viruses. J Gen Virol 1995;76:1877-84.

14. Lanciotti R, et al. Molecular Evolution and Phylogeny of Dengue-4 Viruses. J Gen Virol 1997;78:2279-86.

15. Instituto Nacional de Salud, Subdirección de Epidemiología, 1991. Comunicación personal

16. Ministerio de Salud e Instituto Nacional de Salud. Informe Quincenal Epidemiológico Nacional (IQEN). Bogotá: 1997 Oct $15 ; 2(19)$.

17. Ministerio de Salud e Instituto Nacional de Salud. Informe Quincenal Epidemiológico Nacional (IQEN). Bogotá: 1998 Oct $30 ; 3(20)$.

18. World Health Organization. Dengue in the Americas - An Up Date. Weekly Epidemiol Rec 1994;69(24):177-84.

19. Sariol CA, et al. Detection and genetic relationship of dengue virus sequences in seventeen-year-old paraffin-embedded samples from Cuba. Am J Trop Med Hyg 1999;61:994-1000.

20. Lanciotti R, et al. Rapid Detection and Typing of Dengue Viruses from Clinical Samples by Using Reverse Transcriptase-Polymerase Chain Reaction. J Clin Microbiol 1992;30:545-51

21. Chomcczyski P, Sacci N. Single Step Method of RNA Isolation by Acid Guanidium-Thiocyanate-Phenol-Cloroform Extraction. Anal Bichem 1987;162:156-9.

22. Saitou N, Nei M. The neighbor-joining method: a new method for reconstructing phylogenetic trees. Mol Biol Evol $1987 ; 4: 406-25$.

23. Robin Y, et al. Isolement Du Virus de Dengue au Senegal. Ann Virol (Inst. Pasteur) 1980;131 E:149-154.

24. World Health Organization. Dengue Haemorragic Fever in the Democratic Republic of Viet Nam. Dengue News 1. SE Asian W. Fac. Regions, 1976;2:1-6.

25. Rudnick A. Studies of the ecology of Dengue in Malaysia: A Preliminary Report. J Med Ent 1965;2:203-8.

26. Zanotto PM, et al. Population Dynamics of Flaviviruses Revealed by Molecular Phylogenesis. Proc Nat Acad Sci USA 1996;93:548-53.

27. Trent DW, et al. Genetic Variation Among Dengue 2 Viruses of Different Geographic Origin. Virol 1983;128:271-84.

28. Rico-Hesse R, et al. Geographic Distribution of Wild Poliovirus Type 1 Genotipes. Virol 1987;160:311-2.

29. Oberste M, et al. Identification and Genetic Analysis of Panama-Genotype Venezuelan Equine Encephalitis Virus Subtype ID in Peru. Am J Trop Med Hyg 1998;58:41-6.

30. Rota P, et al. Molecular Epidemiology of Measles Virus. Virol 1995;6:379-86. 